\title{
Isolation and characterization of 89 SNP markers in the oriental turtle dove, Streptopelia orientalis
}

\author{
Jiangyong $\mathrm{Qu}^{1} \cdot$ Ruxiao Wang ${ }^{1} \cdot$ Shanshan Wang ${ }^{1} \cdot$ Xiaoyu Guo ${ }^{1} \cdot$ Yutong Cui $^{1} \cdot$ Yuanyuan $\mathrm{Li}^{1}$
}

Received: 10 December 2018 / Accepted: 11 January 2019 / Published online: 21 February 2019

(c) The Author(s) 2019

\begin{abstract}
Streptopelia orientalis is an important commercial species, and natural populations have declined dramatically in recent years because of the application of traditional Chinese medicine. The effective conservation and management of S. orientalis have been limited without sufficient molecular markers. In this study, we reported the isolation and characterization of 89 SNP markers in S. orientalis. The minor allele frequency raged from 0.0417 to 0.4792 . The observed heterozygosity and expected heterozygosity ranged from 0.0000 to 0.9583 and from 0.0816 to 0.5098 , respectively. Polymorphic information content ranged from 0.0767 to 0.3746 . The inbreeding coefficient values varied from -0.3149 to 0.8686 . Only four loci showed significant deviations from the Hardy-Weinberg equilibrium $(\mathrm{P}<0.05)$. The polymorphic SNPs will be helpful for the further population genetic analysis and natural resource conservation of $S$. orientalis.
\end{abstract}

Keywords Streptopelia orientalis $\cdot$ SNP markers $\cdot$ Population genetic diversity $\cdot$ Transcriptome

The oriental turtle dove (Streptopelia orientalis) is a widespread polytypic Asian species that breeds from the Ural Mountains to the Pacific coast of the Russian Far East (Brazil 2009; Gibbs et al. 2001; Johnson et al. 2001; Lee et al. 2017). S. orientalis has been listed in the International Union for Conservation of Nature (IUCN), IUCN Red List of Threatened Species (2016), ranging from north (Heilongjiang Province) to south (Hainan Island), and from west (Xinjiang and Tibet) to east (Hong Kong and Taiwan). Although $S$. orientalis has not yet been classified as an endangered species, natural populations have declined dramatically in recent years because of the application of traditional Chinese medicine and commercial values. Therefore, it is urgent to perform population genetic investigation on $S$. orientalis to conserve and utilize the natural resources. As an important DNA marker, single nucleotide polymorphisms (SNPs) are widely used for genetic studies (Vignal et al. 2002). In this study, SNPs were developed and characterized in S. orientalis for the first time with the restriction-site associated DNA tags sequencing (RAD-seq), and will be important genetic markers for the researches on conservation genetics.

Jiangyong Qu

springqjy@126.com

1 College of Life Sciences, Yantai University, Yantai 264005, Shandong, China
Blood was collected from $30 \mathrm{~S}$. orientalis individuals from Yantai in Shandong province $\left(37^{\circ} 27^{\prime} \mathrm{N} / 121^{\circ} 30^{\prime} \mathrm{E}\right)$. Genomic DNA was extracted from blood samples using the DNeasy Blood \& Tissue kit (QIAGEN, Germany) according to the manufacturer's instructions. RAD library construction, sample indexing and pooling followed for the natural populations (Baird et al. 2008). To obtained SNP marker resources, pair-end (150-bp) sequencing was performed using Illumina HiSeq4000 (Shanghai BIOZERON Co., Ltd.), and a total of 254, 291 putative SNPs in S. orientalis was identified.

Primer v3.0 was used to design primers, 89 primer pairs successfully created. PCR reactions were performed in a $25 \mu \mathrm{l}$ volume with GenStar PCR Mix according to the manufacturer's instructions (GeneStar, Beijing, China). PCR amplification cycles were as follows: an initial denaturation at $94{ }^{\circ} \mathrm{C}$ for $5 \mathrm{~min} ; 40$ cycles of $94{ }^{\circ} \mathrm{C}$ for $30 \mathrm{~s}$, annealing for $30 \mathrm{~s}$ (for annealing temperatures of each primer pair, see Table 1) for $30 \mathrm{~s}$, and $72{ }^{\circ} \mathrm{C}$ for $30 \mathrm{~s}$; and a final extension at $72{ }^{\circ} \mathrm{C}$ for $7 \mathrm{~min}$. Amplified samples were purified by gel extraction and sequenced on ABI 3730 DNA Analyzer (Applied Biosystems). For validated loci, statistics including the minor allele frequency (MAF), observed heterozygosity $\left(H_{O}\right)$, expected heterozygosity $\left(H_{E}\right)$, polymorphism information content (PIC), inbreeding coefficient $\left(F_{I S}\right)$ and $\mathrm{P}$-value representing the deviations from Hardy-Weinberg 


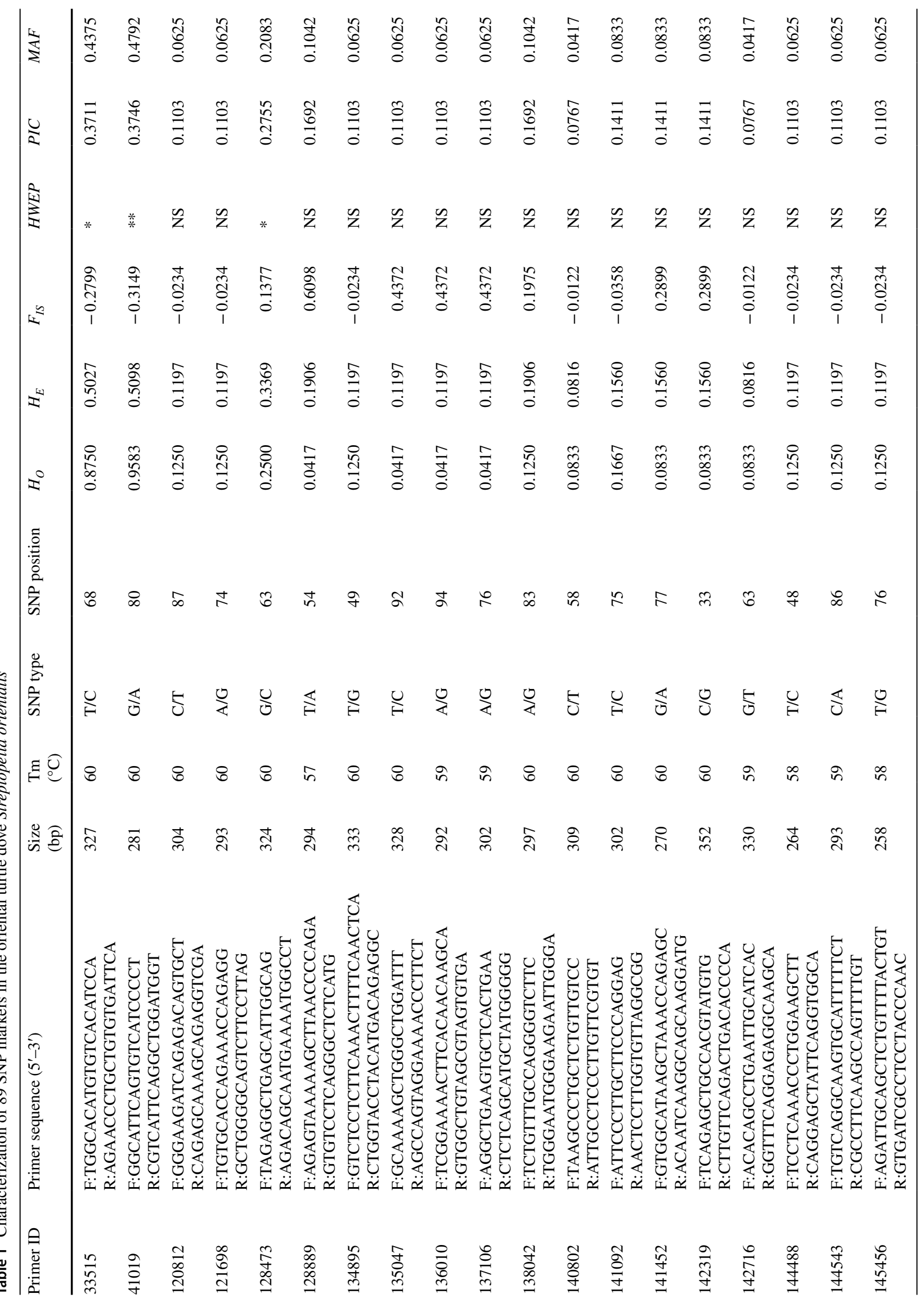




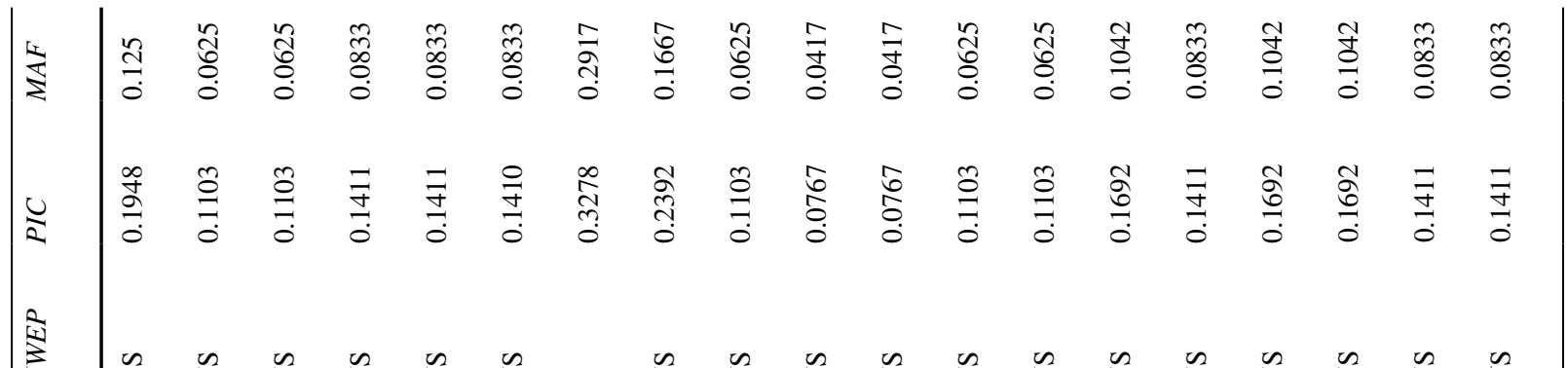

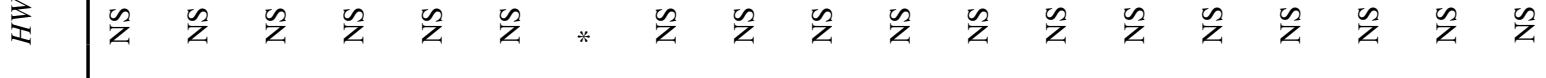

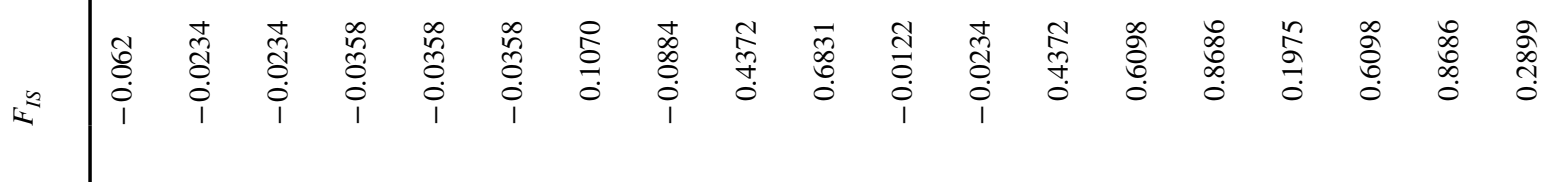

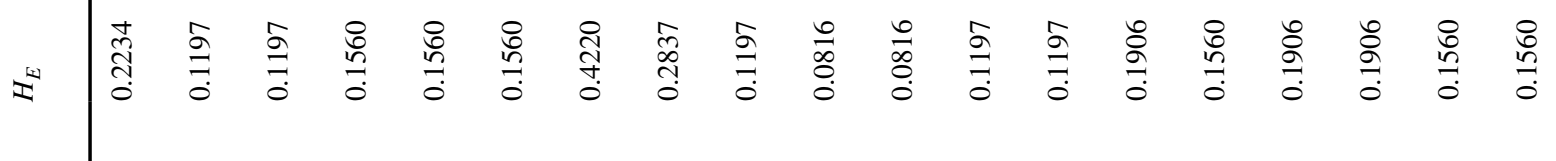

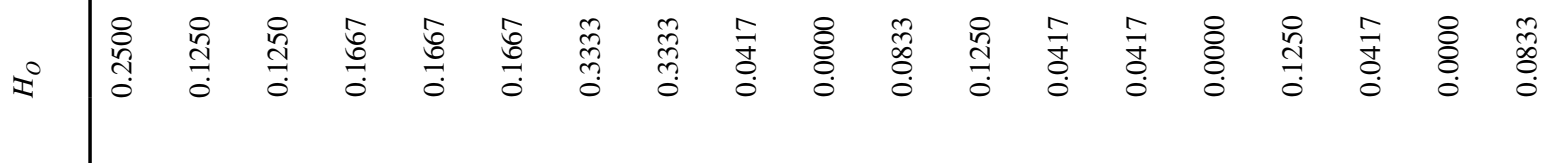

$$
\begin{aligned}
& \text { : } \\
& \text { 芸 }
\end{aligned}
$$

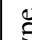

$$
\begin{aligned}
& \text { 言 }
\end{aligned}
$$

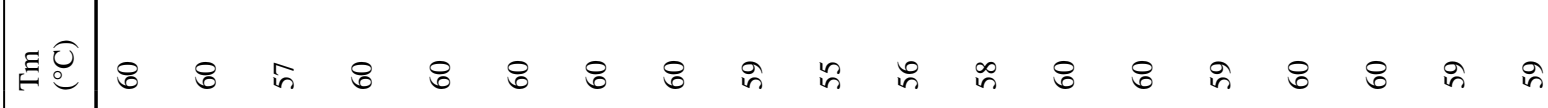

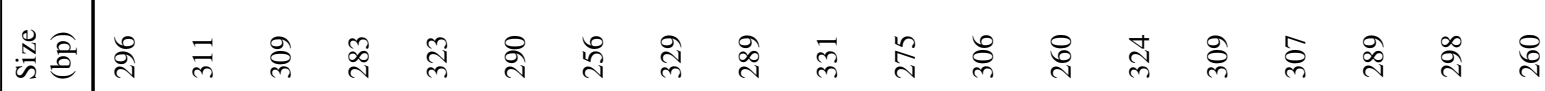

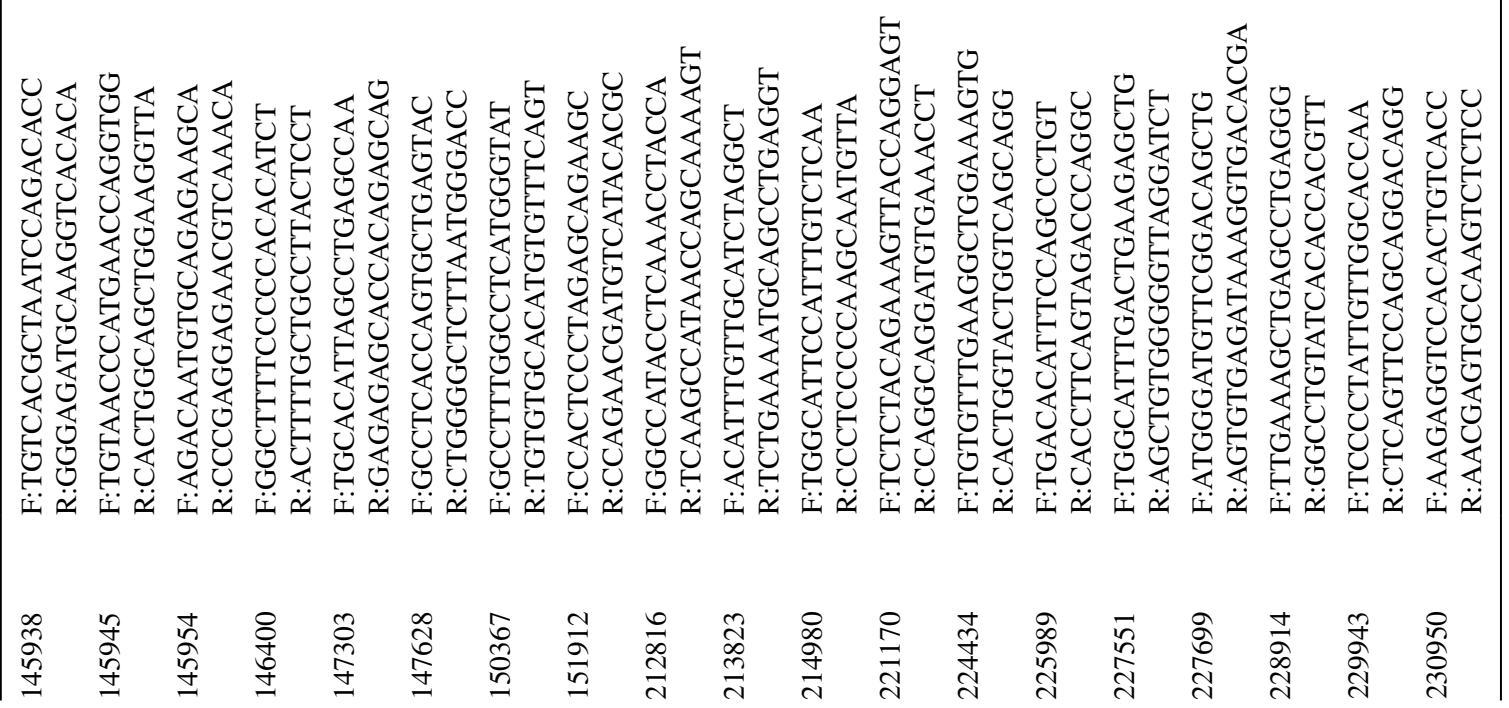




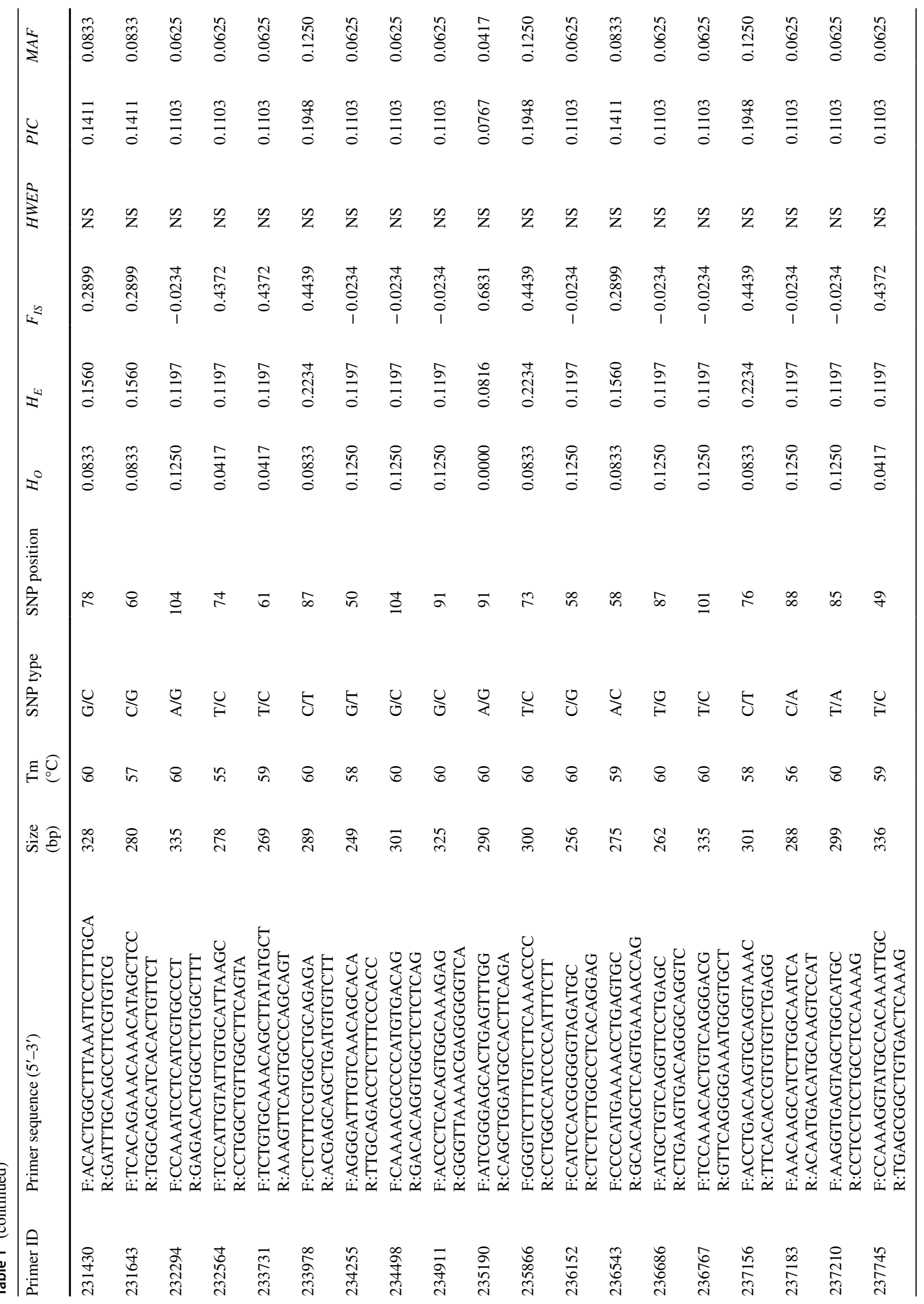




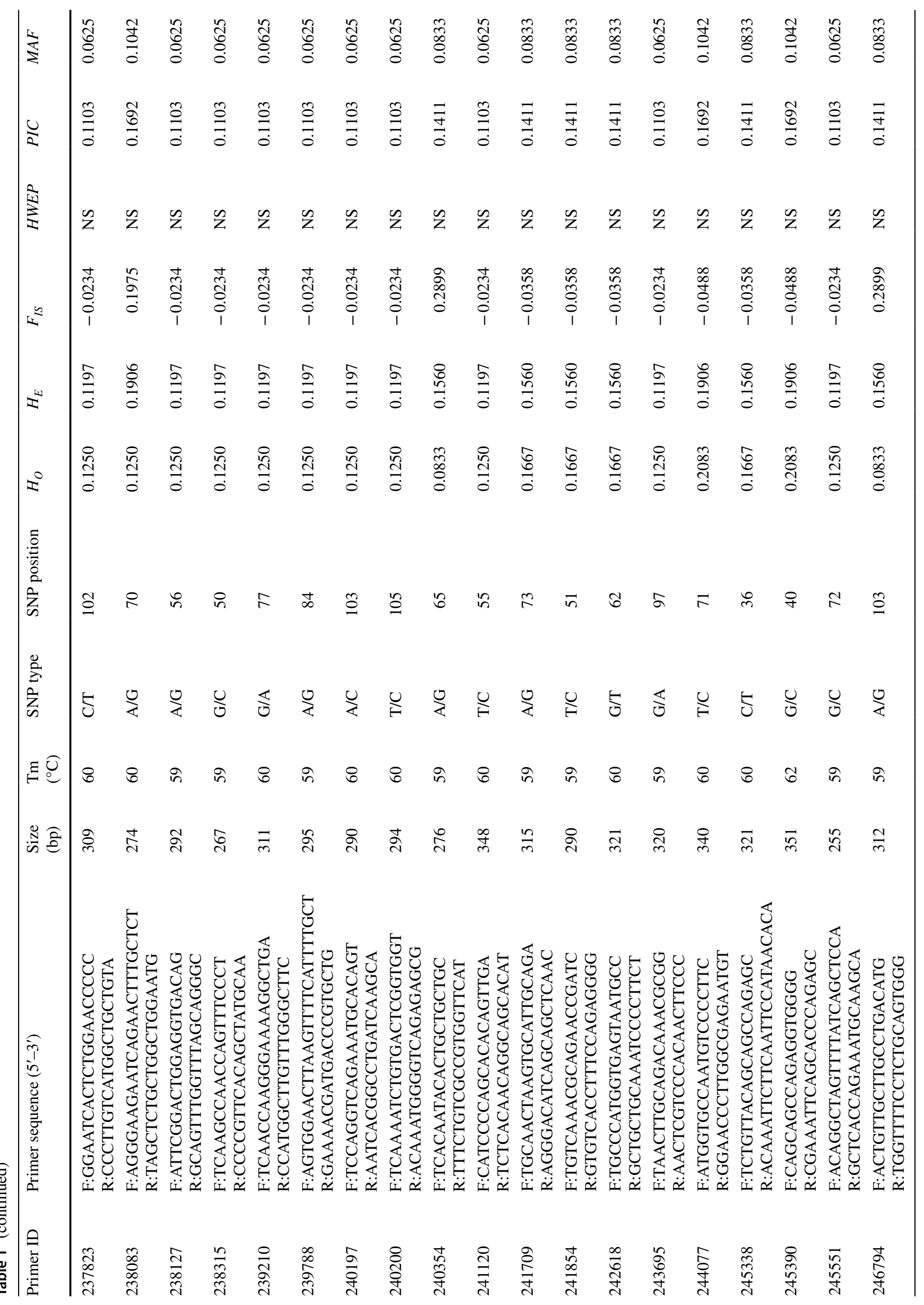




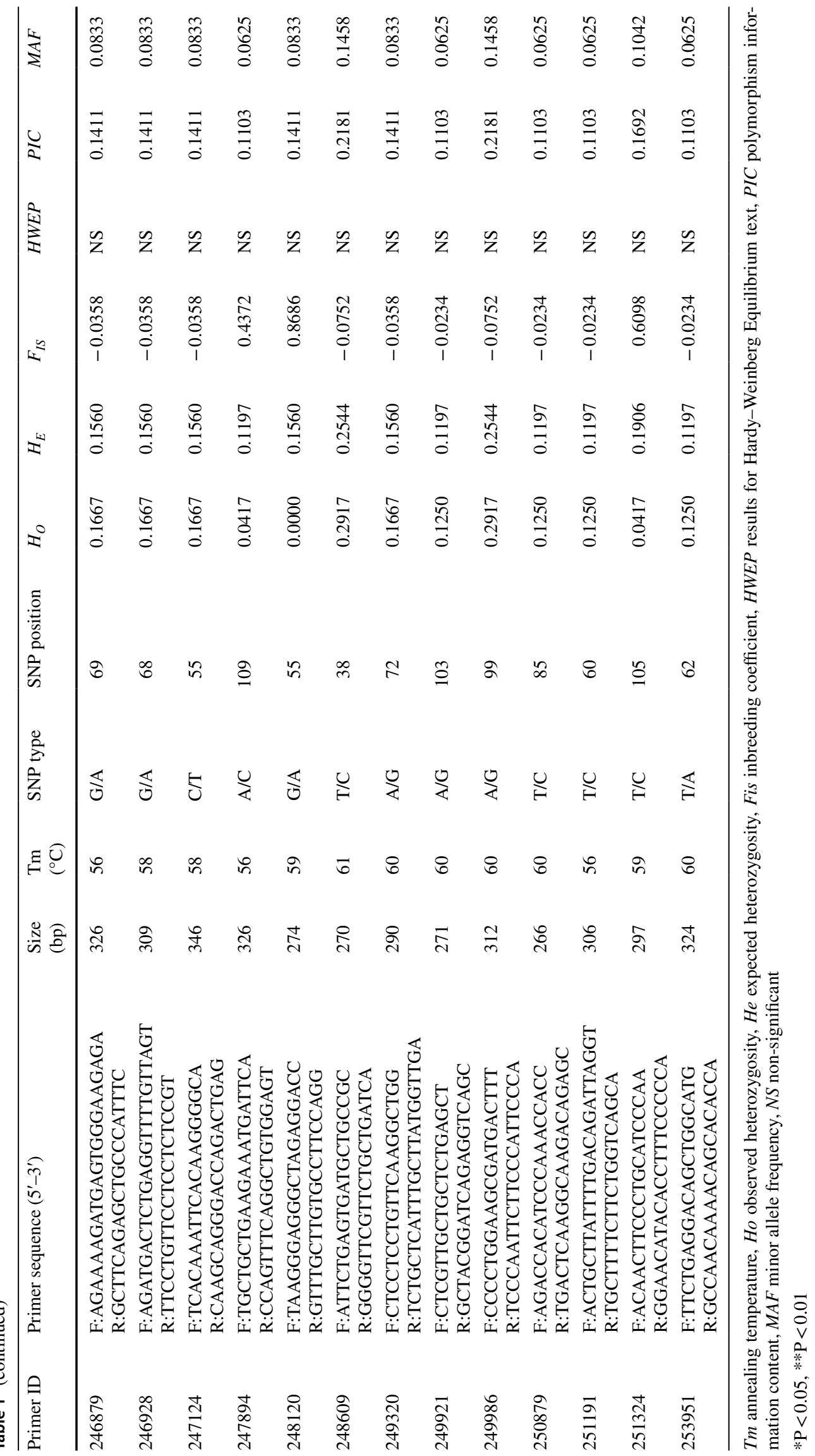


equilibrium (HWEP) were caltulated using Cervus 3.0 (Kalinowski et al. 2007).

Eighty-nine primer pairs could be amplified, and 89 SNPs located within these sequences were confirmed by Sanger sequencing. The minor allele frequency raged from 0.0417 to 0.4792 (Table 1 ). The observed heterozygosity and expected heterozygosity ranged from 0.0000 to 0.9583 and from 0.0816 to 0.5098 , respectively. Polymorphic information content ranged from 0.0767 to 0.3746 . The $F_{I S}$ values varied from -0.3149 to 0.8686 . Only four loci showed significant deviations from the HWE after Bonferroni correction $(\mathrm{P}<0.05)$. These polymorphic SNP markers will be useful for further population genetic analysis, natural resource conservation and selective breeding of $S$. orientalis.

Acknowledgements This work was supported by National Natural Science Foundation of China (No.: 31460562), the Key Research Program of Yantai (SM17SK04, SM17SK09), and the Doctoral Science Research Foundation of Yantai University (SM15B01).

Open Access This article is distributed under the terms of the Creative Commons Attribution 4.0 International License (http://creativeco mmons.org/licenses/by/4.0/), which permits unrestricted use, distribution, and reproduction in any medium, provided you give appropriate credit to the original author(s) and the source, provide a link to the Creative Commons license, and indicate if changes were made.

\section{References}

Baird NA, Etter PD, Atwood TS, Currey MC, Shiver AL, Lewis ZA, Selker EU, Cresko WA, Johnson EA (2008) Rapid SNP discovery and genetic mapping using sequenced RAD markers. PLoS ONE 3(10):e63376. https://doi.org/10.1371/journal.pone.0003376

Brazil M (2009) Birds of East Asia: eastern China, Taiwan, Korea, Japan, eastern Russia. Christopher Helm, London

Gibbs D, Barnes E, Cox J (2001) Pigeons and doves: a guide to the pigeons and doves of the world. Pica Press, Robertsbridge

IUCN (2016) The IUCN red list of threatened species. Version 2016-3. Available at: http://www.iucnredlist.org. Accessed 7 Dec 2016

Johnson KP, De Kort S, Dinwoodey K, Mateman AC, Cate CT, Lessells CM, Clayton DH (2001) A molecular phylogeny of the Dove Genera Streptopelia and Columba. Auk 118(4):874-887

Kalinowski ST, Taper ML, Marshall TC (2007) Revising how the computer program CERVUS accommodates genotyping error increases success in paternity assignment. Mol Ecol 16:1099-1106

Lee HR, Koo BS, Kim JT, Kim HC, Kim MS, Klein TA, Shin MS, Lee SH, Jeon EO, Min KC, Lee SB, Bae YN, Mo IP (2017) Molecular epidemiology of avian poxvirus in the oriental turtle dove (Streptopelia orientalis) and the biting midge (Culicoides arakawae) in the Republic of Korea. J Wildl Dis 53(4):749-760. https://doi. org/10.7589/2016-10-230

Vignal A, Milan D, SanCristobal M, Eggen A (2002) A review on SNP and other types. of molecular markers and their use in animal genetics. Genet Sel Evol 34:275-305. https://doi. org/10.1186/1297-9686-34-3-275

Publisher's Note Springer Nature remains neutral with regard to jurisdictional claims in published maps and institutional affiliations. 